\title{
DIRETRIZES CURRICULARES DE ENFERMAGEM: GOVERNANDO CORPOS DE ENFERMEIRAS
}

\author{
Fernanda Niemeyer ${ }^{1}$, Karen Schein da Silva², Maria Henriqueta Luce Kruse ${ }^{3}$
}

\footnotetext{
${ }^{1}$ Mestre em Enfermagem. Rio Grande do Sul, Brasil. E-mail: fernandaniemeyer@yahoo.com.br

${ }^{2}$ Mestre em Enfermagem. Enfermeira do Serviço de Enfermagem Médica do Hospital de Clínicas de Porto Alegre (HCPA). Rio Grande do Sul, Brasil. E-mail: karen.schein@gmail.com

${ }^{3}$ Doutora em Enfermagem. Coordenadora do Grupo de Enfermagem do HCPA. Professora Associado da Escola de Enfermagem da Universidade Federal do Rio Grande do Sul. Rio Grande do Sul, Brasil. E-mail: kruse@uol.com.br
}

RESUMO: Diretrizes Curriculares objetivam a organização de cursos e carreiras para a constituição de identidades profissionais. Nesse sentido, as Diretrizes Curriculares Nacionais para o Ensino de Graduação em Enfermagem definem os fundamentos para a formação de enfermeiras no Brasil apontando para o tipo de conhecimento considerado importante na profissão. Nos apoiamos nos pressupostos da obra de Michel Foucault para realizar uma análise textual dos discursos veiculados pelas Diretrizes Curriculares de Enfermagem, problematizando-os como uma estratégia de governamento e subjetivação que atua sobre os corpos das futuras enfermeiras. As reflexões apontam para um documento que pode ser visto como um instrumento que pretende normalizar as alunas e constituí-las para que se tornem enfermeiras. Assim, é definido o perfil da "boa" e da "má" profissional, normalizando os corpos e suas atitudes, não as permitindo pensar e fazer de outro modo e instituindo um "regime de verdades" que produz certo tipo de enfermeira.

DESCRITORES: Educação em enfermagem. Discurso. Papel do profissional de enfermagem. Governo

\section{CURRICULAR DIRECTIVES FOR NURSING: GOVERNING NURSES' BODIES}

\begin{abstract}
Curricular Directives aim to organize courses and careers towards establishing professional identities. In this sense, the National Curricular Directives for Undergraduate Nursing Education define the foundations for the education of nurses in Brazil, pointing out the knowledge considered important for the profession. We base ourselves on the presuppositions found in Michel Foucault's work to carry out a textual analysis of the discourses conveyed by the Curricular Directives for Nursing, questioning them as a strategy to govern and subjectivize that acts upon the bodies of future nurses. The reflections herein point towards a document that can be seen as an instrument that intends to normalize students and constitute them to become nurses. Thus, the profile of a "good" and a "bad" professional is defined, normalizing bodies and attitudes, not allowing them to think and create another way and instituting a "regime of truth" that produces a certain type of nurse.
\end{abstract}

DESCRIPTORS: Nursing education. Discourse. Role of nursing professionals. Government

\section{DIRECTRICES CURRICULARES DE ENFERMERÍA: GOBERNANDO CUERPOS DE ENFERMERAS}

RESUMEN: Directrices Curriculares objetivan la organización de cursos y carreras para la constitución de identidades profesionales. En este sentido, las Directrices Curriculares Nacionales para la Enseñanza de Grado en Enfermería definen los fundamentos para la formación de enfermeras en el país, apuntando al tipo de conocimiento considerado importante en la profesión. Nos apoyamos en los presupuestos de la obra de Michel Foucault para realizar un análisis textual de los discursos difundidos por las Directrices Curriculares de Enfermería, problematizándolos como una estrategia de gobernar y de hacer subjetivo que actúa sobre los cuerpos de las futuras enfermeras. Las reflexiones apuntan a un documento que se puede ver como un instrumento que pretende normalizar a las alumnas y constituirlas para que se vuelvan enfermeras. Así se define el perfil de la "buena" y de la "mala" profesional, sistematizando los cuerpos y sus actitudes, sin permitirles que piensen y que hagan las cosas de otro modo e instituyendo un "régimen de verdades" que produce cierto tipo de enfermera.

DESCRIPTORES: Educación en enfermería. Discurso. Papel del profesional de enfermería. Gobierno. 


\section{UM INÍCIO DE CONVERSA}

"A modernidade é o que é - uma obsessiva marcha adiante - não porque sempre queira mais, mas porque nunca consegue o bastante; não porque se torne mais ambiciosa e aventureira, mas porque suas aventuras são mais amargas e suas ambições frustradas. A marcha deve seguir adiante porque qualquer ponto de chegada não passa de uma estação temporária". 1:18

Gostaríamos de iniciar esse trabalho instigando enfermeiras*, professoras de escolas de Enfermagem e estudantes de enfermagem a refletir a respeito da constituição da identidade de enfermeira edificada ao longo da formação acadêmica, e sobre uma "certa" formatação "e obsessiva marcha adiante" pretendida pelas Diretrizes Curriculares que regulamentam os cursos de Enfermagem no Brasil. O Ministério da Educação ${ }^{2}$ afirma que as Diretrizes Curriculares objetivam a organização de cursos e carreiras no que tange à formação dos discentes. Na perspectiva desse órgão do governo, tais Diretrizes funcionam na condução dos cursos de graduação, através de "orientações para a elaboração dos currículos que devem ser necessariamente respeitadas por todas as instituições de ensino superior" ${ }^{\prime 2: 2}$ As Diretrizes Curriculares compreendem pressupostos que norteiam o ensino através da delimitação do que deve ser transmitido e de que modo deve dar-se essa transmissão. ${ }^{3}$ Nesse sentido, as "Diretrizes Curriculares Nacionais para o ensino em nível de Graduação em Enfermagem definem os princípios, fundamentos, condições e procedimentos da formação de enfermeiros" . 4:1

Há algum tempo refletimos acerca das questões relacionadas ao ensino, especialmente de Enfermagem, bem como sobre os processos pedagógicos que envolvem a formação da profissional enfermeira. Pensamos que somos constantemente subjetivadas pelos discursos pedagógicos que nos atravessam e que (con)formam não apenas nossas mentes e ações, mas também controlam nossos corpos. Dessa forma, compreendemos o currículo como artefato que está comprometido com a produção de representações e identidades culturais, incluindo aí as identidades profissionais, pois na constituição do currículo é possível encontrar o tipo de conhecimento considerado importante para que se molde o profissional tido como "ideal" ${ }^{3,5}$
O currículo tornou-se alvo de muitos debates no meio acadêmico. Juntamente com as instituições de ensino, esse instrumento tem sido responsabilizado pelos sucessos e fracassos na educação. Uma das finalidades fundamentais de toda intervenção curricular é preparar as alunas para serem cidadãs ativas e críticas. ${ }^{6}$ Nesse sentido, o currículo de enfermagem visa formar um tipo de "profissional qualificado para o exercício de Enfermagem [...]. Capacitado a atuar, com senso de responsabilidade social e compromisso com a cidadania, como promotor da saúde integral do ser humano". ${ }^{4: 1}$ Uma meta desse tipo exige, por conseguinte, que a seleção dos conteúdos do currículo promova a construção dos conhecimentos, destrezas, atitudes, normas e valores necessários para ser o chamado "bom" profissional. Dessa maneira, tendo em vista o atual contexto do ensino em enfermagem, o objetivo foi estudar os discursos pedagógicos veiculados pelas Diretrizes Curriculares de Enfermagem para problematizá-los como uma estratégia de governamento e subjetivação que atua sobre os corpos das futuras enfermeiras. Pensamos que "o currículo pode ser visto como texto e analisado como discurso, uma vez que constitui um espaço e um campo de produção e de criação de significados" "7:28

Nesse sentido pretendemos ler no documento que regulamenta as Diretrizes Curriculares de Enfermagem o que o seu discurso "faz", o que ele objetiva, a respeito de que ele fala. Dessa forma, desejamos demonstrar por quais modos de sujeição as estudantes são incitadas a construir certa corporeidade profissional - pensando, assim, nas Diretrizes Curriculares de Enfermagem como um dos possíveis modos de governamentalização, que viria ao encontro de um Estado neoliberal.

Gostaríamos de esclarecer que nossa intenção, ao analisar esse documento, não foi fazer uma crítica às ideias ali contidas, nem colocá-las em cheque ou tentar provar sua veracidade ou falsidade, mas sim destacar algumas idéias que nos permitiram abrir nossa "caixa de ferramentas" foucaultianas para discorrer sobre esse tema. O conceito de caixa de ferramentas foi desenvolvida por Michel Foucault como algo que deveria funcionar, mas não apenas para si mesma, como algo que deveria ser útil, pois se ninguém pudesse utilizá-la como instrumento de auxílio é porque ainda não havia chegado o seu momento. ${ }^{8}$ Nesse aspecto,

\footnotetext{
* Utilizaremos as nomenclaturas que se referem às profissionais de enfermagem, bem como às estudantes e professoras de enfermagem, no feminino, uma vez que, embora a presença masculina venha aumentando na profissão, nesses últimos anos, as mulheres ainda estão em maior número.
} 
utilizaremos algumas noções e conceitos desenvolvidos pelo filósofo como ferramentas para analisar as Diretrizes Curriculares de Enfermagem.

\section{NOSSOS CAMINHOS}

Este texto trata-se de uma análise textual que se inscreve no campo dos estudos culturais pós-estruturalistas, especialmente na vertente inspirada em Michel Foucault. Esta perspectiva pós-moderna compõe um conjunto de ações descentradas e instáveis que propõe uma análise externa à racionalidade moderna e define-se como uma multiplicidade de tendências em vários meios da cultura colocando em suspeita as "verdades" e grandes narrativas da modernidade. ${ }^{7}$ Esse tipo de análise pode contribuir para que se detectem indícios de uma episteme, entendida por Foucault como um dos conjuntos básicos de regras que governam a produção de discursos numa determinada época. Assim, a função da análise textual seria mostrar os diferentes significados que estariam atrelados na produção de sujeitos, já que esse tipo de análise pretende tratar diferentes espaços do mundo contemporâneo como artefatos pedagógicos, sendo a escola apenas um deles. $\mathrm{Ou}$ seja: imagens, filmes, televisão, textos escritos, incluindo aí as Diretrizes Curriculares de Enfermagem, são considerados artefatos pedagógicos que nos constituem. ${ }^{9}$

Assim, esse estudo consiste na associação entre alguns textos do referencial teórico pós-estruturalista e o último documento que regulamenta as Diretrizes Curriculares de Enfermagem, datado de 7 de novembro de 2001. Para a análise dos dados realizamos uma leitura interessada do material a qual trata "[...] de saber aquilo que podemos aproveitar e aquilo que podemos descartar, deixar passar ou deixar de lado". 10:17 Para analisar nossos recortes, nos apoiamos em alguns pressupostos da obra de Michel Foucault, especialmente nos seus entendimentos acerca de disciplina, governamento, sujeito e discurso. Para o filósofo, a disciplina poderia ser entendida como um mecanismo de controle do exercício do poder, como uma forma de domar os corpos dos indivíduos tornando-os governáveis. ${ }^{11-12}$ Já governamento seria a maneira de governar a conduta dos indivíduos ou dos grupos. Embora Foucault não utilize o termo governamento, e sim governo, nós utilizaremos o primeiro com o objetivo de diferenciar o governo das condutas daquele Governo relacionado à instância política. ${ }^{13}$ Partiremos do entendimento de sujeito como um objeto-objetivo, como ser sujeitado e constituído, produto histórico e social produzido pelas relações de poder e saber. ${ }^{14}$ Por fim, o termo discurso será compreendido como conjunto de enunciados que respondem a uma mesma formação discursiva de acordo com um regime de verdade. Os discursos são dotados de poderes e subjetivam os indivíduos. ${ }^{15-16}$

\section{PROBLEMATIZANDO ENUNCIADOS}

Instituir, definir, aplicar, orientar, desenvolver, fazer e promover são alguns dos verbos presentes nas Diretrizes Curriculares de Enfermagem, que tem o objetivo de incitar as futuras enfermeiras a realizarem tais ações. Notamos, através desses verbos, o esforço que esse documento faz para, mais do que transformar, normalizar alunas de Enfermagem, constituí-las para que se tornem enfermeiras, com todos os sentidos que essa profissão poderia carregar. Assim, ao formar profissionais dentro desses padrões curriculares, as Diretrizes de Enfermagem pretendem fabricar corpos de profissionais críticas e resolutivas, não apenas no âmbito da saúde, mas também em relação às demais questões que permeiam o meio social, sendo capazes de intervir tanto nas questões individuais como nas coletivas. Exemplificamos tal enunciado através do inciso I do artigo 14, extraído do documento em questão: "A estrutura do Curso de Graduação em Enfermagem deverá assegurar: [...] a articulação entre o ensino, pesquisa e extensão/ assistência, garantindo um ensino crítico, reflexivo e criativo, que leve à construção do perfil almejado, estimulando a realização de experimentos e/ou de projetos de pesquisa; socializando o conhecimento produzido, levando em conta a evolução epistemológica dos modelos explicativos do processo saúde-doença". $4: 5$

Para Foucault, o poder, para exercer-se em mecanismos sutis, como a instituição de um documento regulador de uma profissão, forma, organiza e põe em circulação um saber, ou melhor, aparelhos de saber que não são construções ideológicas. ${ }^{11}$ Dessa maneira, as Diretrizes de Enfermagem instituem mais do que ideias; instituem práticas, modos de ser. De acordo com o filósofo, a prisão poderia ser compreendida como uma fábrica de delinquentes. ${ }^{11}$ Nesse sentido, poderíamos considerar que a educação também fabricaria sujeitos de determinado tipo, nesse caso, voltados especialmente para a lógica neoliberal que pretenderia fazer do sujeito o mais útil possível. Como exemplo, podemos observar o que diz o inciso XXXII do artigo $5^{\circ}$, das Diretrizes Curriculares de 
Enfermagem: "A formação do enfermeiro tem por objetivo dotar o profissional dos conhecimentos requeridos para o exercício das seguintes competências e habilidades específicas: [...] cuidar da própria saúde física e mental e buscar seu bemestar como cidadão e como enfermeiro". 4:3 Aqui, podemos entender que a enfermeira deve gozar de saúde física e mental para que possa ser útil, para que tenha condições de exercer seu papel e para que não traga ônus para a sociedade. Mas como fazer isso dentro da lógica neoliberal que rege o mercado profissional? Como obter o máximo uso dos corpos sem causar danos à saúde? Pensamos as Diretrizes de Enfermagem como um documento comprometido com a "governamentalidade" neoliberal, uma vez que os sujeitos desse discurso deverão ter corpos produtivos, úteis e econômicos.

No documento também é possível observar o uso de um vocabulário bastante semelhante ao utilizado por cursos e empresas da área de marketing e administração, sugerindo que, além de tornarem-se enfermeiras, as alunas teriam de desenvolver um bom marketing pessoal e habilidades gerenciais para que suas atividades administrem tanto suas vidas quanto as vidas das pessoas que cuidam. Assim, a repetição de expressões como responsabilidade, capacidade, competências, habilidades, liderança, empreendedorismo, gerenciamento, desenvolvimento, entre outras tantas, que remetem ao sentido de um sujeito "empresário de si", bem como a citação do termo "cliente", já bastante conhecido, ao invés do mais tradicional "paciente" ou "usuário". É importante ressaltar que, para Foucault, o sujeito "empresário de si" seria aquele sujeito que funcionaria como seu próprio capital e seu próprio produtor. Ele mesmo seria a fonte de sua própria renda, calculando os ganhos e as perdas, permanentemente, para si mesmo. ${ }^{17}$ Em suma, o sujeito "empresário de si" se autogerencia e se autogoverna. Retomamos o inciso I, do artigo $3^{\circ}$, que coloca o tipo de formação que as Diretrizes Curriculares de Enfermagem objetivam: "[...] profissional qualificado para o exercício de Enfermagem [...], capacitado a atuar, com senso de responsabilidade social e compromisso com a cidadania, como promotor da saúde integral do ser humano". 4:1 Assim, para ser uma "boa" profissional, a enfermeira deveria assumir determinados atributos e características, pois esse documento interpela as futuras profissionais objetivando formatá-las para que elas se responsabilizem por manter uma determinada "ordem" no setor saúde.
Assim, as Diretrizes Curriculares de Enfermagem imprimem em nossos corpos "formas de ser e habitar o mundo, isto é, formas de viver e ser saudável provenientes de saberes sobre o corpo, que, além de atingirem os corpos dos pacientes, se exercem também sobre os nossos próprios corpos". ${ }^{7-24}$ Desta forma, concordamos com Foucault, quando diz que "efetivamente, aquilo que faz com que um corpo, gestos, discursos e desejos sejam identificados e constituídos enquanto indivíduos é um dos primeiros efeitos de poder. Ou seja, o indivíduo não é o outro do poder: é um de seus primeiros efeitos. O indivíduo é um efeito do poder e simultaneamente, ou pelo próprio fato de ser um efeito, é seu centro de transmissão. O poder passa através do indivíduo que ele constituiu" .11:184

O currículo pode ser pensado como um dos dispositivos pedagógicos que interpela o corpo das futuras enfermeiras (en)formando-as e governando-as de acordo com as lógicas do mercado, fabricando e adestrando seus corpos. Desta maneira, apesar da aparente (in)visibilidade dos corpos constituídos no/pelo currículo, acreditamos que o corpo da profissional de enfermagem vai sendo investido e moldado nas Escolas de Enfermagem, as quais funcionam como maquinarias colocadas em operação a fim de produzir a enfermeira. Maquinaria poderia ser entendida como uma complexa engrenagem formada por um conjunto de máquinas que fabricam, nesse caso, nossos corpos. ${ }^{18}$ Podemos compreender tal conjunto como práticas discursivas que, ao se articularem, criam verdades sobre os sujeitos. É nas Escolas de Enfermagem, e nos documentos que as regulamentam e as produzem que aprendemos a ser e a nos comportar como enfermeiras. Assim, embora pareça um pouco problemático raciocinar a respeito desse investimento feito no corpo e corporeidade dos profissionais de enfermagem, acreditamos que problematizar essas questões possa ser produtivo, uma vez que somos o reflexo desse espelho que aí está, somos as engrenagens que auxiliam na produção desses sujeitos e, ao mesmo tempo, somos o produto corporificado de tudo isso.

Pensamos que é através de uma rede de saberes na qual o corpo se insere que se estabelecem relações de poder que organizam os sistemas de classificação nos quais estamos inseridos, o que nos auxilia a ocuparmos o nosso devido lugar para entrar no jogo e pertencer a um determinado "regime de verdade".${ }^{19} \mathrm{Ou}$ seja, entramos para uma rede discursiva que fala sobre nós, produz aquilo que somos ou deveríamos ser e determina nossas 
identidades. Os discursos sobre as Diretrizes Curriculares de Enfermagem se endereçam aos futuros profissionais de enfermagem e definem o perfil do "bom" e do "mau" profissional, normalizando esses corpos e suas atitudes, não os permitindo ponderar e fazer de outro modo, bem como os avaliando constantemente.

O documento ainda destaca que as avaliações das alunas serão feitas com base nas resoluções ali instituídas, conforme parágrafo $1^{\circ}$ do artigo 15: "As avaliações dos alunos deverão basear-se nas competências, habilidades e conteúdos curriculares desenvolvidos, tendo como referência as Diretrizes Curriculares". 4:6 Assim, tal documento regula, modela e governa esses corpos, desde o início de sua formação profissional, para que o resultado seja alcançado com maior êxito. Essas questões relativas aos investimentos nos corpos nos fazem perceber os corpos de enfermeiras como corpos dóceis, conforme desenvolvido por Foucault, ou seja, um corpo possível de ser manipulado e, portanto, mais facilmente governado. ${ }^{20} \mathrm{Um}$ corpo "que pode ser submetido, que pode ser utilizado, que pode ser transformado e aperfeiçoado". 20:126 Deste modo, ao invés de emanarem práticas sociais, econômicas, culturais e políticas a partir do sujeito, o corpo passa a ser derivado a partir dessas práticas, aqui vistas como práticas discursivas.

Para interpelar as estudantes de enfermagem e tramar uma rede discursiva mais entranhada, o documento ainda aciona alguns discursos, já bastante conhecidos na área da saúde, tais como os discursos da humanização, da interdisciplinaridade e da integralidade da assistência, objetivando modelar as futuras enfermeiras. Podemos identificar esse tipo de enunciado no inciso I do artigo $4^{\circ}$ do documento: "[...] Cada profissional deve assegurar que sua prática seja realizada de forma integrada e contínua com as demais instâncias do sistema de saúde, sendo capaz de pensar criticamente, de analisar os problemas da sociedade e de procurar soluções para os mesmos". .:1 $^{4}$

As Diretrizes Curriculares de Enfermagem explicitam algumas das idéias desenvolvidas por Michel Foucault em seu curso "Nascimento da Biopolítica" ${ }_{17}^{17}$ no que se refere à política neoliberal. O Neoliberalismo objetiva um Estado mínimo agindo no coletivo, que cada vez mais dilui suas funções estatais na população, a qual deve estar em sintonia com as questões econômicas, a economia dos usos - melhor proveito com o menor custo.

A vida contemporânea e as transformações econômicas e sociais fabricaram um sujeito que
Foucault chamou de Homo oeconomicus, que seria o sujeito comprometido com a política neoliberal. $\mathrm{Na}$ ordem desse discurso, as Diretrizes Curriculares de Enfermagem estão em consonância com o neoliberalismo e o Homo oeconomicus, pois a enfermeira deve ser capaz de autogovernar suas condutas, seu comportamento, seu tempo, suas atividades, deve se autorregular, pois sua vida é a sua empresa a qual ela precisa administrar. Assim, esse sujeito enfermeira torna-se seu próprio "cartão de visita" e, por isso, é preciso gerir-se cuidando de sua saúde, educando-se, desenvolvendo competências: aprendend o a aprender, aprendendo a fazer, aprendendo a ser, aprendendo a conhecer, o que "constitui atributos indispensáveis à formação do Enfermeiro" 4:6 Tais atributos seriam indispensáveis para que o jogo econômico seja jogado e para que essa profissional possa se tornar competitiva. Dessa forma, esse sujeito moderno (sujeito enfermeira) deve ser autônomo, pois ele será o único responsável pelo seu sucesso ou pelo seu fracasso. Podemos observar tal enunciado no artigo $9^{\circ}$ das Diretrizes Curriculares de Enfermagem: "O Curso de Graduação em Enfermagem deve ter um projeto pedagógico, construído coletivamente, centrado no aluno como sujeito da aprendizagem e apoiado no professor como facilitador e mediador do processo ensino-aprendizagem" . $^{4: 5}$

Ao longo do documento a ênfase na questão das competências, que deveriam ser desenvolvidas pelas estudantes, também chama a atenção. Considerando o sentido linguístico de "competência" poderíamos entender esse conceito não só como uma série de aptidões necessárias, mas também como o ato de concorrer de competir. ${ }^{21}$ Dessa maneira, quando o documento trata do desenvolvimento de competências, além de estimular habilidades "inerentes" à profissão, também estaria determinando que aquela profissional mais habilidosa tivesse as melhores ferramentas para competir dentro dessa lógica de mercado. Um exemplo desse discurso pode ser observado no parágrafo $2^{\circ}$ do artigo $6^{\circ}$, das Diretrizes: “Este conjunto de competências, conteúdos e habilidades deve promover no aluno e no enfermeiro a capacidade de desenvolvimento intelectual e profissional autônomo e permanente" . 4:4

Para que o indivíduo se torne esse "empresário de si", o documento também estimula o desenvolvimento de competências e habilidades através de mecanismos de conhecimentos, como consta no artigo $8^{\circ}$ : “O projeto pedagógico do Curso de Graduação em Enfermagem deverá contemplar 
atividades complementares [...]: monitorias e estágios; programas de iniciação científica; programas de extensão; estudos complementares". ${ }^{4: 5}$ Deste modo, pensamos que um currículo que clama por competências e habilidades pode estar se baseando em determinada noção de competência, não sendo possível estabelecer o que caracterizaria uma formação profissional relacionada a determinado tipo de atenção à saúde. ${ }^{3}$ Além disso, as palavras "competência" e "habilidade" possuem longa história no campo da educação, levando-nos a questionar qual o significado de sua recolocação nas Diretrizes Curriculares.

\section{O QUE FICA DE TUDO ISSO?}

As Diretrizes Curriculares de Enfermagem pretendem instituir um determinado "regime de verdade" que acaba naturalizado na Academia. Não se questiona o fato das coisas serem feitas/ pensadas de uma maneira e não de outra, pois existe um documento que dita essas regras: um documento normalizador de condutas. Esse mecanismo de poder apoia-se nos corpos e seus atos. É um mecanismo que permite extrair dos corpos tempo e trabalho. É um poder que atua disciplinarmente, através de um sistema minucioso de coerções disciplinares que garante, efetivamente, a coesão deste mesmo corpo social. Para Foucault ${ }^{11}$ as disciplinas ou, nesse caso, as Diretrizes, são criadoras de aparelhos de saber e de múltiplos domínios de conhecimento. São métodos que permitem o controle minucioso das operações do corpo, que realizam sua sujeição constante e que lhes impõem uma relação de docilidade-utilidade. ${ }^{20}$ Elas veiculam um discurso que é o da regra "natural", ou seja, da norma. Definem um código da normalização - um tipo de poder e de saber que a sacralização científica neutraliza.

Dessa maneira, as Diretrizes de Enfermagem pretendem formar certo tipo de profissional estabelecendo determinados padrões e critérios, funcionando como um instrumento, ao mesmo tempo regulador, regulamentador, normalizador e normatizador que age sobre os corpos, tanto de professoras, quanto das acadêmicas de enfermagem. Regulamentador e normatizador, pois sendo um documento que parte de uma iniciativa política nacional, regulamenta, em termos legais e políticos, o tipo de currículo e formação que deverão receber as profissionais de enfermagem no país. Normalizador e regulador, pois, ao estabelecer normas e regras para a formação profissional, esse documento passa a regular as condutas dos sujeitos envolvidos nesse processo de educação e, além disso, passa a estabelecer uma norma na formação de enfermeiras - norma que os indivíduos não podem ou não devem escapar. Assim, as Diretrizes Curriculares de Enfermagem podem ser vistas como uma ferramenta comprometida com a política neoliberal, pois pretendem produzir profissionais que se autogovernem. Elas atingem os corpos dos indivíduos, se inserem em seus gestos, suas atitudes, seus discursos e sua aprendizagem. ${ }^{11}$

Nesse texto não pretendemos estabelecer verdades acerca dessa temática, mas mostrar os modos como esses discursos produzem efeitos de verdades, subjetivam e objetivam as enfermeiras. Tentamos tornar problemático um documento que apresenta certos pressupostos como intrínsecos ao projeto pedagógico, apontando para a existência de uma "vontade" de produzir enfermeiras com uma determinada identidade profissional. ${ }^{3}$ Não podemos mais olhar o currículo de forma inocente, pois ele é lugar, espaço, território, relação de poder. É autobiografia, texto, discurso. É documento de identidade. ${ }^{5}$ Assim, ao operar sobre os corpos e moldá-los, as Diretrizes Curriculares de Enfermagem imprimem um regime discursivo que captura as profissionais e não lhes permite ser e pensar de outro modo sobre suas práticas e identidade.

\section{REFERÊNCIAS}

1. Bauman Z. Modernidade e ambivalência. Rio de Janeiro (RJ): Jorge Zahar; 1999.

2. Ministério da Educação (BR), Conselho Nacional de Educação, Câmara de Educação Superior. Parecer CNE/CES n 776 de 3 de dezembro de 1997: orientação para as Diretrizes Curriculares dos Cursos de Graduação. Brasília (DF): MEC; 1997 [acesso 2009 Out 21]. Disponível em: http:/ / portal. mec.gov.br/cne/arquivos/pdf/CES0776.pdf

3. Kruse MHL, Meyer DEE. Acerca de diretrizes curriculares e projetos pedagógicos: um início de reflexão. Rev Bras Enferm. 2003 Jul-Ago; 56(4):335-9.

4. Ministério da Educação (BR), Conselho Nacional de Educação, Câmara de Educação Superior. Resolução $\mathrm{CNE} / \mathrm{CES} \mathrm{n}^{\circ} 3$ de 7 de novembro de 2001: Diretrizes Curriculares Nacionais do Curso de Graduação em Enfermagem. Brasília (DF): MEC; 2001 [acesso 2008 Out 23]. Disponível em: http:/ / portal.mec.gov.br/ cne/arquivos/pdf/CES03.pdf

5. Silva TT. Teorias do currículo: uma introdução crítica. Portugal (PT): Porto Editora; 2000.

6. Santomé JT. As culturas negadas e silenciadas no currículo. In: Silva TT, organizador. Alienígenas 
na sala de aula: uma introdução aos estudos culturais em educação. Petrópolis (RJ): Vozes; 1995. p.159-77.

7. Kruse MHL. Os poderes dos corpos frios: das coisas que se ensinam às enfermeiras. Brasília (DF): ABEn; 2004.

8. Foucault M. Un dialogo sobre el poder. Madrid (ES): Alianza Editorial; 2000.

9. Costa MV, Silveira RH, Sommer LH. Estudos culturais, educação e pedagogia. Rev Bras Educ. 2003 Mai-Ago; 23: 36-61.

10. Fischer RMB, Veiga-Neto A. Foucault, um diálogo. Educ Realidade. 2004 Jan-Jun; 29(1):7-25.

11. Foucault M. Microfísica do poder. Rio de Janeiro (RJ): Graal; 2005.

12. Machado R. Introdução. In: Foucault M. Microfísica do poder. Rio de Janeiro (RJ): Graal; 2005. p.7-13.

13. Veiga-Neto A. Coisas do governo... In: Rago $M$, Orlandi L, Veiga-Neto A, organizadores. Imagens de Foucault e Deleuze: ressonâncias nietzschianas. Rio de Janeiro (RJ): DP\&A; 2002. p.13-34.
14. Albuquerque Júnior DM. Michel Foucault ou como nos tornamos sujeitos. Rev Educ. 2007 Mar; 1(3):84-9.

15. Fischer RMB. Foucault e a análise do discurso em educação. Cad Pesqui. 2001 Nov; 144: 197-223.

16. Foucault M. A ordem do discurso: aula inaugural no Collège de France, pronunciada em 2 de dezembro de 1970. São Paulo (SP): Loyola; 2006.

17. Foucault M. Nacimiento de la biopolítica: curso en el Collège de France: 1978-1979. Buenos Aires (AR): Fondo de Cultura Econômica; 2007.

18. Varela J, Alvarez-Uría F. A maquinaria escolar. Rev Teoria Educ. 1992; 6: 68-96.

19. Andrade SS. Mídia, corpo e educação: a ditadura do corpo perfeito. In: Meyer DEE, Soares RFR, organizadoras. Corpo, Gênero e Sexualidade. Porto Alegre (RS): Mediação; 2004.

20. Foucault M. Vigiar e punir: nascimento da prisão. Petrópolis (RJ): Vozes; 1983.

21. Dicionário da língua portuguesa [online]. Lisboa (PT): Priberam Informática; 2008 [acesso 2008 Out 23]. Disponível em: http://www.priberam.pt/ dlpo/definir_resultados.aspx 